\title{
Humoral Immune Response in Mice Elicited by Combined Yeast-Derived Hepatitis B Virus Core, Surface, and Mosaic Surface Antigens
}

\author{
Vladimir Granovskia Jonny Yokosawa ${ }^{a}$ b Vanessa Rodrigues-Granovskia \\ Carlos Cueto Castro ${ }^{c}$ Alfonso Camacho Urbina ${ }^{c}$ Nikolai Granovski ${ }^{a}$ \\ ${ }^{a}$ NL Biotechnologies LLC, North Little Rock, Arkansas, AR, USA; ${ }^{b}$ Instituto de Ciências Biomédicas, Universidade

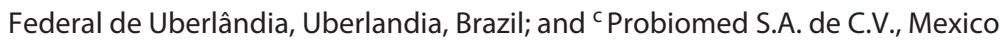

\section{Keywords}

Hepatitis B vaccine · preS1 · preS2 - Hepatitis B surface antigen · Hepatitis B core antigen · Hepatitis B virus immunology

\begin{abstract}
Background: Although successful, the second-generation hepatitis $B$ vaccine programs around the world have a small group of immunized individuals that does not respond efficiently to the vaccination. Other issues of these vaccines are individuals that are low or nonresponders and/or have incomplete protection against heterologous hepatitis $B$ virus (HBV) genotypes/subtypes and against HBV escape mutants. In addition, there are approximately 240 million people chronically infected with HBV worldwide and 620,000 deaths per year caused by the infection. Methods: In this study we developed three Hansenula polymorpha plasmids containing the following sequences: (a) HBsAg subtype ayw, (b) HBcAg sequence subtype adw2, and (c) chimeric HBsAg (adw4/ ayw) - preS1 (adw2) - 3 repetitions of preS2 (genotypes A, B, and $C$ ). The sequences were successfully expressed and the antigens purified. Using Balb/c mice the antigens were tested in different dosage combinations. Results: Three antigens were obtained at a high purity level and with high re-
\end{abstract}

\section{KARGER}

(C) 2017 S. Karger AG, Basel

E-Mail karger@karger.com

www.karger.com/int producibility. We also assessed their immunogenic properties, showing that theantigens, individuallyorincombination, generated anti-HBs, anti-preS1, anti-preS2, and anti-HBc antibodies efficiently in mice. Conclusions: The formulation tests showed that a combination of $0.02 \mu \mathrm{g}$ of $\mathrm{HBs}, 0.2 \mu \mathrm{g}$ of preS1-preS2-HBs, and $0.02 \mu \mathrm{g}$ of $\mathrm{HBc}$ was effective in eliciting specific antibodies in mice.

(c) 2017 S. Karger AG, Basel

\section{Introduction}

Hepatitis B is still a major concern in public health, with a worldwide estimate of 240 million people chronically infected with the hepatitis B virus (HBV) and nearly 620,000 carriers die per year due to the disease [1]. HBV transmission may occur from infected mothers to their newborns, mainly at birth. The transmission also occurs through sexual activities and ruptures of the skin, including blood transfusions, injecting drug use, tattooing, accidents involving needles/scalpels in health care settings, and others. While most people who become infected with HBV during adulthood eliminate the virus naturally, over $90 \%$ of infants infected at birth suffer from persistent infection [2]. 
The treatment of chronic hepatitis B has improved considerably in the last 15 years, owing to new antiviral compounds that demonstrate an effective level of inhibition of HBV replication and have low or absent development of resistance [3]. However, although current antiviral therapies alter the progression of liver fibrosis and reduce the occurrence of hepatocellular carcinoma (HCC), a sustained cure is not possible and long-term use of the current antivirals is associated with the selection of drugresistant mutations in the viral genome [4].

$\mathrm{HBV}$ is a DNA virus with RNA as the replication intermediate and belongs to the Hepadnaviridae family. $\mathrm{HBV}$ is classified into 9 genotypes, A thorough to I, and based on HBsAg heterogeneity and 9 serological subtypes: ayw1, ayw2, ayw3, ayw4, ayr, adw2, adw4, adwq, adr, and adrq- [5]. The virion is approximately $42 \mathrm{~nm}$ in diameter. The envelope contains 3 antigens: the small (S) hepatitis B surface antigen (HBsAg) and 2 less abundant proteins with higher molecular weights, the medium (M) HBsAg, which besides the $S$ sequence contains an extension of 55 amino acid (aa) residues named preS2 at its Nterminus, and the large (L) HBsAg, which contains an additional 108 or 119 aa (depending on the HBV subtype) called preS1 besides the preS2 and $S$ sequences $[6,7]$. The capsid has icosahedral symmetry and is constructed of the core $(\mathrm{C})$ protein. In addition to these proteins, the 3.2$\mathrm{kb}$ genome encodes the viral DNA polymerase, the hepatitis $\mathrm{B}$ e antigen ( $\mathrm{HBeAg}$ ), and the $\mathrm{X}$ protein.

To date, three generations of the HBV vaccine have been developed. In the first-generation vaccine, the HBsAg was purified from plasma of chronic carriers [8] and was dissuaded by the World Health Organization (WHO) due to the limitation in plasma supply and to the risk of infection caused by any remaining virus in the vaccine [9]. The advances in recombinant DNA technologies in the mid-1980s led to the successful expression of the S gene, initially in Saccharomyces cerevisiae, and later in other yeast expression systems. This second-generation vaccine has exceptional immunogenicity and protective efficacy [10-13] and has been used in approximately half of the world's countries in their vaccination programs. Third-generation vaccines contain preS1 and preS2 epitopes in addition to $\mathrm{S}$ antigen and are considerably more immunogenic than the second-generation ones. These vaccines are suitable for nonresponders to the conventional vaccines $[11,14,15]$. Approximately $10-15 \%$ of the normal population fails to produce hepatitis B antibody titer above $10 \mathrm{mIU} / \mathrm{mL}$, which is the critical titer for protection against the infection, regardless of how many doses are administered $[16,17]$. These nonresponders in-

Yeast-Derived New-Generation HBV

Vaccine clude people who work in health care settings and may be exposed to HBV.

Because $\mathrm{HBV}$ core antigen ( $\mathrm{HBcAg}$ ) is known to induce strong immune responses in hepatitis B-infected individuals [18], it has been proposed as a potential component of a prophylactic and/or therapeutic HBV vaccine as well as a carrier of foreign epitopes, such as the ones of foot-andmouth disease and dengue viruses, for vaccine development [19-21]. In an HBV challenge experiment using chimpanzees immunized with a bacteria-expressed HBcAg, 1 of the animals was completely protected and the other was substantially protected against the infection [22].

In addition to low and nonresponders to available vaccines, incomplete protection against diverse HBV genotypes/subtypes and against virus mutants that emerge as the result of pressure due to mass immunization, as well as the use of ineffective therapeutic drugs, are important issues to public health $[3,23,24]$. Therefore, it is imperative to develop a new HBV vaccine that may provide improved protection for low or nonresponders and against the higher number of HBV variants/mutants, and for chronically infected patients, which may stimulate the immune system to eliminate the virus. In this study, we developed three Hansenula polymorpha plasmids containing the following sequences: (a) HBsAg subtype ayw (273 aa), (b) HBcAg sequence subtype adw2 (185 aa), and (c) chimeric 299 aa HBsAg (adw4/ayw) - preS1 (adw2) -3 repetitions of preS2 (genotypes A, B, and C). The plasmids were successfully expressed and the antigens purified. Using Balb/c mice, the antigens were tested in different dosage combinations until an optimal dose was determined.

\section{Materials and Methods}

\section{Plasmids}

For expression of small HBsAg (226 aa), plasmid $\mathrm{H}$ (pH-HB) was used to transform cells of the methylotrophic yeast $H$. polymorpha. In addition to the LEU2 marker, ColE1 origin of replication, and ampicillin selection marker, this plasmid contained the coding sequence of the small HBsAg sequence of subtype ayw, the promoter and the transcription terminator sequences of the methanol oxidase gene, and an autonomously replicating sequence (HARS) of H. polymorpha [25].

For expression of the mosaic preS1-preS2-HBs antigen (BankIt2018595 Seq1 MF155964), pH-HB was used as the vector and the HBsAg coding sequence was replaced with the coding sequence of preS1 (from aa position 21 to 47 of HBV of genotype A/ subtype adw2, GenBank accession No. X70185), followed by 3 preS2 sequences (from aa 131 to 145 of $\mathrm{HBV}$ of genotypes $\mathrm{C}$ [D00630], A [X51970], and B [D23677], respectively), and by fulllength small HBsAg of subtypes adw4 (aa 1-177 of HBsAg) and

Intervirology 2017;60:90-101

DOI: $10.1159 / 000480509$ 


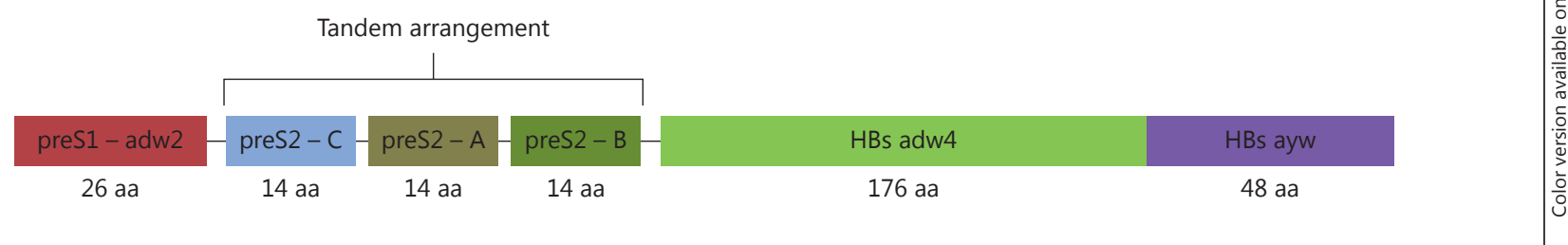

Fig. 1. The chimeric preS1-preS2-HBs structure containing the coding sequence for expression of the preS1 sequence of HBV surface antigen of genotype A from aa position 21-47 (sequence in red), followed by 3 preS2 sequences of $\mathrm{HBV}$, of genotypes $\mathrm{C}$ (sequence in blue), $\mathrm{A}$ (sequence in brown), and $\mathrm{B}$ (sequence in dark

ayw (aa 178 to 226). The cloned sequence coded for the preS1preS2-HBs protein contains 299 aa residues (Fig. 1).

For the expression of $\mathrm{HBcAg}, \mathrm{pH}-\mathrm{HB}$ was also used as the vector for cloning the entire $\mathrm{HBcAg}$ coding sequence (185 aa) from a plasmid containing the full genome sequence of $\mathrm{HBV}$ of subtype adw2/genotype A (GenBank accession No. AM282986).

\section{Genetic Transformation, Stability, and Cell Bank}

\section{Establishment}

Approximately $15 \mu \mathrm{g}$ of each plasmid DNA was digested with the $B s i \mathrm{WI}$ restriction enzyme, a unique site present in the plasmids in the HARS region, and the linearized plasmids were used individually for transformation of the leucine auxotrophic mutant of $H$. polymorpha DL-1 cells [26] using a protocol described elsewhere [27]. We did not carry out cotransformation with 2 or more plasmids due to unsynchronized and uncontrolled expression of the target proteins in a unique clone observed in other studies performed at our laboratory (data not shown). After transformation, cells were plated onto a selective medium containing a $0.67 \%$ yeast nitrogen base without aa, 1.5\% D-glucose (1X YNBD), and $2 \%$ agar. Approximately 6 days after transformation, several colonies were selected for plate selection in 4 passages. The most uniform and well-isolated colonies (clones) were cultivated in $1 \mathrm{X}$ YNBD until the cell suspension reached an $\mathrm{OD}_{600}$ of 1.0-1.2. Then, glycerol was added to $20 \%$ to the suspensions and aliquots were stored at $-80^{\circ} \mathrm{C}$ (master cell bank). For genetic stability testing, an aliquot of the master cell bank was inoculated in 1X YPD (1\% yeast extract, $2 \%$ peptone, $2 \%$ dextrose) and the culture was incubated overnight at $30^{\circ} \mathrm{C}$ and $220 \mathrm{rpm}$. An aliquot of the culture was plated in $1 \mathrm{X}$ YNBD and 50 individual colonies were further cultivated in 2 plates, 1 containing $1 X$ YNBD and the other $1 X \mathrm{YNBD} / 40 \mu \mathrm{g} / \mathrm{mL}$ L-leucine. The clones were considered genetically stable if at least 49 colonies (98\%) showed propagation in both plates.

\section{Expression of HBsAg, preS1-preS2-HBs, and HBc}

An aliquot of the master cell bank was propagated in $50 \mathrm{~mL}$ of $1 \mathrm{X} Y N B D$ for $36 \mathrm{~h}$ at $30^{\circ} \mathrm{C}$ and $220 \mathrm{rpm}$. The suspension was transferred to $250 \mathrm{~mL}$ of $1 \mathrm{X} \mathrm{YPD}$ (similar to $1 \mathrm{X}$ YPD, but containing $1 \%$ dextrose). After $24 \mathrm{~h}$ at $30^{\circ} \mathrm{C}$ and $220 \mathrm{rpm}$, the second suspension was transferred to $400 \mathrm{~mL}$ of $\mathrm{Y}_{4} \mathrm{P}_{2} \mathrm{G}_{1}$ (4\% yeast extract, $2 \%$ peptone, and $1 \%$ glycerol) and incubated for a further $24 \mathrm{~h}$. The third suspension was inoculated in $4.6 \mathrm{~L}$ of $\mathrm{Y}_{4} \mathrm{P}_{2} \mathrm{M}_{0.5}$ ( $4 \%$ yeast extract, $2 \%$ peptone, $0.5 \%$ methanol) and the fermentation was car- green), from aa position 131-145 arranged in tandem, and the fulllength small HBsAg (or just S) sequence of subtype adw4 (aa 1-177 of HBsAg) in green and ayw (aa 178-226) in purple. The cloned fragment contains the coding sequence of 897 nucleotides and codes for a protein containing 299 aa.

ried out at $30^{\circ} \mathrm{C}$ in a Bioflo 110 Fermentor (New Brunswick). Dissolved oxygen was maintained at $15 \%$ by using an RPM ramp and, later, by $\mathrm{O}_{2}$ injection. Induction was performed by adding methanol to the bioreactor when the dissolved $\mathrm{O}_{2}$ level rose above $15 \%$. At the end of the induction process (from 90 to $120 \mathrm{~h}$ ), the culture was centrifuged at 9,000 $\mathrm{g}$ for $20 \mathrm{~min}$, the supernatant was discarded, and the cell biomass was stored at $-80^{\circ} \mathrm{C}$ for at least $4 \mathrm{~h}$ before the purification process.

\section{Purification of Yeast-Expressed HBV Antigens}

One hundred grams of biomass was resuspended with $400 \mathrm{~mL}$ of disruption buffer ( $50 \mathrm{mM} \mathrm{Na} \mathrm{HPO}_{4}, 3 \mathrm{M}$ Urea, $10 \mathrm{mM}$ EDTA, 0.5\% Tween 20, pH 7.0) and disrupted using the Gaulin APV 2000 series at 1,200 bar. The progress of cell disruption was monitored by measuring the $\mathrm{OD}_{280}$ of the suspension and the temperature controlled not to pass above $36^{\circ} \mathrm{C}$. The lysate was centrifuged at $9,000 \mathrm{~g}$ for $20 \mathrm{~min}$ at $8^{\circ} \mathrm{C}$ and the supernatant was submitted to ultrafiltration with a $300-\mathrm{kDa}$ Millipore membrane until a quarter of the original volume remained. The concentrate was dialyzed against 10 volumes of $10 \mathrm{mM}$ of phosphate buffer (PB; $\mathrm{pH} 7.0$ ). Next, $4 \mathrm{M}$ of $\mathrm{HCl}$ was added to the sample until the $\mathrm{pH}$ reached $5.8-5.9$, when most of the proteins in the preparation precipitated while the target antigens (all target proteins had the same behavior during the precipitation) remained soluble. After centrifugation at $22,000 \mathrm{rpm}$ for $15 \mathrm{~min}$ at $4^{\circ} \mathrm{C}$, the supernatant was recovered and, after the $\mathrm{pH}$ was adjusted to 9.3 with $2 \mathrm{M} \mathrm{NaOH}$, injected in ionexchange chromatography using DEAE Sepharose Fast Flow resin (General Electric) preequilibrated with $\mathrm{PB}$. The unbound fraction, containing the target proteins (all target proteins had the same net charge and behaved similarly), was harvested in the flow-through and submitted to isopycnic $\mathrm{KBr}$ gradient centrifugation at 37,864 $g$ for $22 \mathrm{~h}$. Then, 2 -mL fractions were harvested using a multichannel microperistaltic pump and analyzed by enzyme-linked immunosorbent assay (ELISA) to detect the target proteins (the buoyant density of all target proteins were approximately the same).

For ELISA, individual wells were coated with approximately $100 \mu \mathrm{L}$ of each fraction and incubated for $1 \mathrm{~h}$ at $37^{\circ} \mathrm{C}$. After washing 5 times with PBST (PBS, 0.05\% Tween 20), the wells were blocked with $300 \mu \mathrm{L}$ of blocking buffer (PBS, $10 \%$ normal goat serum and $2 \%$ bovine serum albumin) at $37^{\circ} \mathrm{C}$ for $1 \mathrm{~h}$. After washing 5 times with PBST, the wells were incubated for $1 \mathrm{~h}$ at $37^{\circ} \mathrm{C}$ with $100 \mu \mathrm{L}$ of the monoclonal antibodies (mAbs) anti-HBsAg (obtained from the Departamento de Biotecnologia, Universidad 
Autónoma de México, Mexico), anti-preS1 (sc57762, Santa Cruz), anti-preS2 (Ab9335, Abcam), or anti-HBc (HCM-021-5, US Biological), diluted $1: 1,000$ in PBST/2\% BSA, except for the latter, which was diluted 1:500. The wells were washed 5 times with PBST and incubated with $100 \mu \mathrm{L}$ of goat horseradish peroxidase-conjugated anti-mouse IgG (KPL) diluted $1: 10,000$ in PBST/2\% BSA at $37^{\circ} \mathrm{C}$ for $1 \mathrm{~h}$. The wells were again washed 5 times with PBST, incubated with $100 \mu \mathrm{L}$ of OPD solution (Sigma-Aldrich) at room temperature for $30 \mathrm{~min}$ and the reaction was stopped by the addition of $50 \mu \mathrm{L}$ of $2.5 \mathrm{M} \mathrm{H}_{2} \mathrm{SO}_{4}$. The plate was read at $\mathrm{OD}_{492}$ in a microplate reader.

Fractions that showed the highest reactivity by ELISA were pooled and submitted to a size-exclusion chromatography (SEC) by injecting the sample into a column packed with $\mathrm{HW}-65 \mathrm{~F}$ resin preequilibrated and eluted with $\mathrm{PB}$. Then, 2-mL chromatographic fractions were harvested, tested by ELISA (using the same methodology as described above), and those with the highest reactivity in ELISA were pooled and concentrated with an Amicon system using $300-\mathrm{kDa}$ Millipore membranes to a concentration between 2.0 and $4.0 \mathrm{mg} / \mathrm{mL}$, and stored at $-80^{\circ} \mathrm{C}$ in $4 \%$ glycerol. High-performance liquid chromatography (HPLC)-SEC was performed using a Waters Alliance 2695 system with a Waters $2489 \mathrm{UV} / \mathrm{Vis}$ detector, using a TSK gel size exclusion column (Tosoh). All peak data were integrated using Empower software (also from Waters). The protein concentration of each antigen was determined by Lowry assay using the $\mathrm{DC}^{\mathrm{TM}}$ Protein Assay (Bio-Rad) following the manufacturer's instructions.

\section{Denatured Polyacrylamide Gel Electrophoresis and Western Blotting}

For SDS-PAGE and Western blot, approximately $10 \mu \mathrm{g}$ of each purified antigen was denatured using Stop buffer (125 mM Tris$\mathrm{HCl}, 2 \% \mathrm{SDS}, 1 \% \mathrm{DTT}, 10 \%$ glycerol, $\mathrm{pH}$ 6.8), and loaded into individual wells in $10 \%$ Mini-PROTEAN ${ }^{\circledR}$ TGX gels (Bio-Rad). After electrophoresis, the gels were either stained with silver nitrate or had the proteins transferred to a PVDF membrane using a Mini Trans-Blot ${ }^{\circledR}$ cell apparatus (Bio-Rad) following the manufacturer's instructions. In short, for staining, a microwave oven was used in all steps for incubating the gels in methanol/acetic acid/formaldehyde solution, $30 \%$ ethanol, distilled water, sodium thiosulfate solution, silver nitrate/formaldehyde solution, distilled water, sodium carbonate/sodium thiosulfate/formaldehyde solution, and methanol/acetic acid/formaldehyde solution. For Western blot, the membranes were blocked for $1 \mathrm{~h}$ at $37^{\circ} \mathrm{C}$ with blocking buffer (the same buffer used in ELISA), then incubated for $1 \mathrm{~h}$ at $37^{\circ} \mathrm{C}$ with $5 \mathrm{~mL}$ of anti-HBs, anti-preS1, anti-preS2, or anti-HBc $\mathrm{mAbs}$ diluted in $\mathrm{PBST} / 2 \%$ BSA at $1: 4,000,1: 800,1: 800$, and $1: 1,000$, respectively. As the negative control, purified pB166 [28], a truncated ORF2 protein of hepatitis E virus (HEAg) fused to glutathione S-transferase expressed in bacteria, was used (with plasmid kindly provided by Dr. Khudyakov, CDC, USA). Membranes were washed 5 times with PBST and incubated with $5 \mathrm{~mL}$ of goat HRP-conjugated anti-mouse IgG diluted $1: 10,000$ in PBST/2\% $\mathrm{BSA}$ at $37^{\circ} \mathrm{C}$ for $1 \mathrm{~h}$. The membranes were washed 5 times with PBST and incubated with $2 \mathrm{~mL}$ of Immobilon Western Chemiluminescent HRP Substrate at room temperature for $30 \mathrm{~min}$. The detection was performed in a dark room using a Hypercassette autoradiography cassette (Amersham) and CL-XPosure ${ }^{\mathrm{TM}}$ film (Thermo). After the exposure, films were developed and fixed using Kodak GBX developer and fixer solutions. Alternatively, mem- branes were stained by DAB (Sigma-Aldrich) following the manufacturer's instructions.

\section{Mouse Immunization}

Groups of 5 or 7 female BALB/c mice, aged 4 weeks, were used in the immunization experiments. The mixtures were first prepared with $20 \mu \mathrm{g}$ of antigen (HBs, preS1-preS2-HBs, or $\mathrm{HBc}$ ), $0.5 \mathrm{mg}$ of $\mathrm{Al}(\mathrm{OH})_{3}$ in $10 \mathrm{~mL}$, and incubated at room temperature for approximately $12 \mathrm{~h}$ (all formulations were made as a human dose based on previous experience with second generation vaccine, and then diluted for administration in mice). Before the immunization, the mixtures were diluted to either $0.02,0.2$, or $0.5 \mu \mathrm{g}$ (individually or in combination) per $0.5 \mathrm{~mL}$, which was the volume of each dose per animal. Each mouse was immunized intraperitoneally with the preparation and, when more than 1 dose was administered, there was an interval of 15 days between the doses. The animals were bled 15 days after the completion of the immunization schedule, and their serum samples were obtained. The use of animals was approved by the Internal Committee for the Care and Usage of Laboratory Animals (CICUAL; September 1, 2015) of Probiomed S.A. de C.V., where the immunization experiments were performed, following official Mexican regulation (NOM062-Z00-1999).

\section{Enzyme-Linked Immunosorbent Assay}

To detect anti-HBs IgG antibodies, the serum samples were tested using Architect i1000sr equipment and the Medical Device ARCHITECT anti-HBs kit (Abbott Diagnostics), following the manufacturer's instructions, and considered reactive to anti-HBs if GMT values were $>10 \mathrm{mIU} / \mathrm{mL}$. To detect anti-preS1 and antipreS2 antibodies, ELISA plate wells were coated with bacteria-expressed preS1 and preS2CA (containing preS2 sequences of genotypes $C$ and $A$ in tandem) segments (the same segments used to construct pSL-S1S2D2m133) obtained as fusion protein with glutathione S-transferase (GST-preS1 and GST-preS2CA, respectively). For this, nucleotide sequences that coded for these segments, with codons optimized for expression in bacteria, were cloned individually into pGEX-4T-2 (GE). The proteins were expressed in BL21 strain, purified with Glutathione Sepharose 4B (GE), and used individually to coat the ELISA plate wells for the detection of either anti-preS1 or anti-preS2 antibodies of the serum of immunized mice. To detect anti-HBc antibodies, the wells were coated with a bacteria-expressed truncated HBcAg (Ab49014, Abcam). Each well of an ELISA plate was coated with $1.0 \mu \mathrm{g}$ of 1 of the proteins (GST-preS1, GST-preS2CA, or HBcAg) in a volume of 100 $\mu \mathrm{L}$ with PBS by incubating at $37^{\circ} \mathrm{C}$ for $1 \mathrm{~h}$. Wells coated with $\mathrm{pB} 166$ (HEAg, described above) were used as negative controls. After washing the wells 5 times with PBST, they were incubated with 300 $\mu \mathrm{L}$ of blocking buffer at $37^{\circ} \mathrm{C}$ for $1 \mathrm{~h}$, washed 5 times with PBST, and incubated for $90 \mathrm{~min}$ at $37^{\circ} \mathrm{C}$ with $100 \mu \mathrm{L}$ of mouse serum diluted 1:20 with PBST/2\% BSA. The subsequent steps were carried out as described above.

\section{Statistical Analysis}

Statistical analyses were performed using GraphPad Prism software version 5.0 (GraphPad Software Inc.). Differences in ELISA OD 492 values of the groups of immunized mice were evaluated by the Kruskal-Wallis test with the Dunn multiple comparison post-test. To examine all possible differences between a test group and the control group, the Kruskal-Wallis with Dunn multiple 


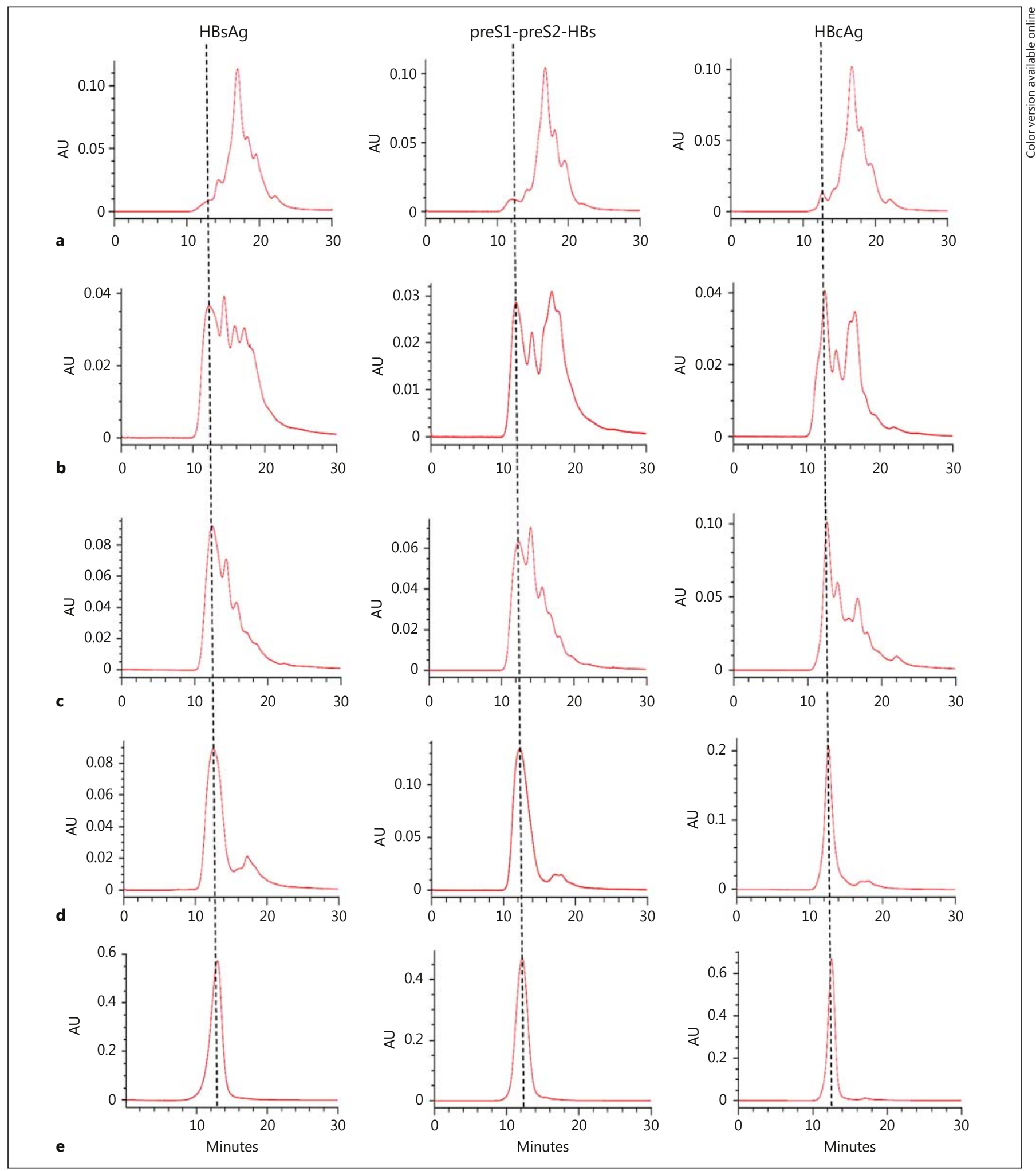

Fig. 2. HPLC-SEC performed after the main steps of the purification process, beginning on top and finishing at the bottom, which represents the final products. a After centrifugation of the cell lysate. b After ultrafiltration with a $300-\mathrm{kDa}$ membrane. c Superna- tant after precipitation with $\mathrm{HCl}$ and centrifugation. $\mathbf{d}$ After ionexchange chromatography. e After SEC. The vertical dashed lines indicate the approximate fractions that contained the expressed antigens shown above. 


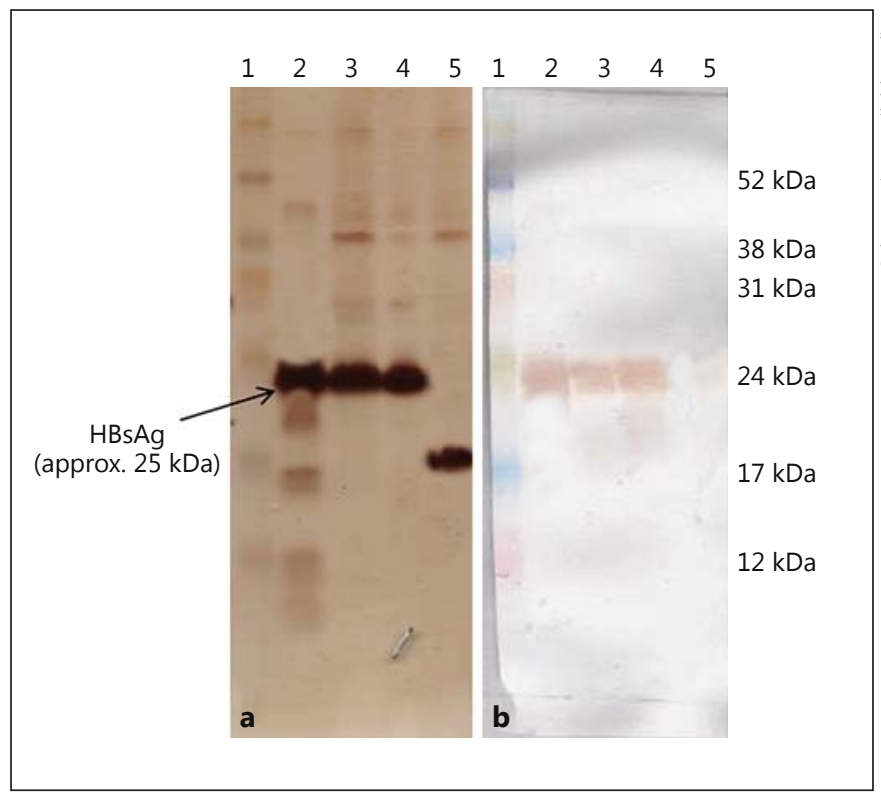

Fig. 3. SDS-PAGE (a) and Western blot (b) of HBsAg preparations. Approximately $10 \mu \mathrm{g}$ of the purified antigen of 3 different preparations (lanes 2, 3, and 4) was submitted to electrophoresis. As the negative control, $1 \mu \mathrm{g}$ of $\mathrm{pB} 166$ (containing truncated ORF2 protein of hepatitis E virus) was used (lane 5). For SDS-PAGE, gel was stained with silver nitrate, and for Western blot, an antiHBsAg mAb was used and the reaction was revealed with DAB. The marker used was Amersham Rainbow RPN756E.

comparison post-test or ANOVA with Bonferroni multiple comparison post-test (parametric) were used. Values of $p<0.05$ were considered statistically significant.

\section{Results}

\section{Expression, Purification, and Evaluation of}

Yeast-Expressed HBV Antigens

Three HBV antigens were constructed and expressed in H. polymorpha. Two of them contained the full length of the small surface and the core antigens. The third antigen also contained a full-length small HBs sequence of a different HBV subtype, and at its $\mathrm{N}$-terminus 1 segment of preS1, followed by 3 segments in tandem of preS2. After induction of the expression using methanol, the cells were collected and disrupted to release the antigens. The purification of the antigen involved centrifugation, removal of low molecular weight molecules by dialysis, acidic precipitation, ion exchange chromatography, gradient centrifugation, and SEC. Aliquots of each step were evaluated by HPLC-SEC and the purified products

Yeast-Derived New-Generation HBV

Vaccine formed a major peak, indicating a high degree of purity of HBsAg, preS1-preS2-HBs, and HBcAg (Fig. 2). The degree of purity was determined as being equal or above $97 \%$. In order to monitor the progress of the purification process, the aliquots were also tested by ELISA with $\mathrm{mAbs}$ against the antigens and showed increasing reactivity after each step, indicating that the antigen ratio in the preparation was increasing (results not shown).

From a 5.3-L culture, approximately $950 \mathrm{~g}$ of cell biomass was obtained for each antigen and a protein yield of approximately $550 \mathrm{mg}$ of HBsAg, $700 \mathrm{mg}$ of preS1-preS2$\mathrm{HBs}$, and $650 \mathrm{mg}$ of HBcAg. Analysis in SDS-PAGE corroborated that the preparation of HBsAg had a high degree of purity, with a major band corresponding to the expected molecular weight (Fig. 3a) and the Western blot using $\mathrm{mAb}$ against HBs (Fig. $3 \mathrm{~b}$ ). The preS1-preS2-HBs preparation also formed a major band in SDS-PAGE (Fig. 4a) and another band, with a lower intensity, probably corresponding to dimers, was also observed, using either anti-preS1 mAbs in Western blots (Fig. 4b). However, blots for preS2 and HBs showed no dimer formation (Fig. 4c, d, respectively). The HBsAg segment of this antigen showed a reduced intensity against anti-HBs $\mathrm{mAb}$, probably due to the lower reactivity of this antibody against the HBs sequence of subtype adw4 (Fig. 4d). The SDS-PAGE and Western blot with HBcAg preparation also showed that the purified product had a high degree of purity and a major band corresponding to the expected molecular weight (Fig. 5a-c).

Immunogenic Properties of HBs, preS1-preS2-HBs, and $H B c$, in Individual and in Combined

\section{Preparations}

The purified antigens were used to prepare different inocula, with individual or the combination of all antigens, for the immunization of mice. After the immunization protocols were completed, the mice were bled and their serum samples were obtained for testing in ELISA.

With mice immunized with HBsAg only $(0.2 \mu \mathrm{g} /$ dose/ animal), samples showed increasing reactivity with an escalating number of doses (Fig. 6a). In addition, all mice seroconverted, even with a single dose of the inoculum.

With the chimeric antigen bearing preS1, preS2, and HBs segments, immunization with $0.2 \mu \mathrm{g}$ of antigen/animal in a single dose was sufficient to elicit anti-HBs antibodies above $10 \mathrm{mIU} / \mathrm{mL}$ (Fig. 6b1), with a seroconversion rate of $100 \%$. For anti-preS 1 antibodies, although the OD values obtained in the group of mice immunized with a unique dose containing $0.2 \mu \mathrm{g} /$ animal were statistically significant in comparison with the control group immu-

Intervirology 2017;60:90-101 95 


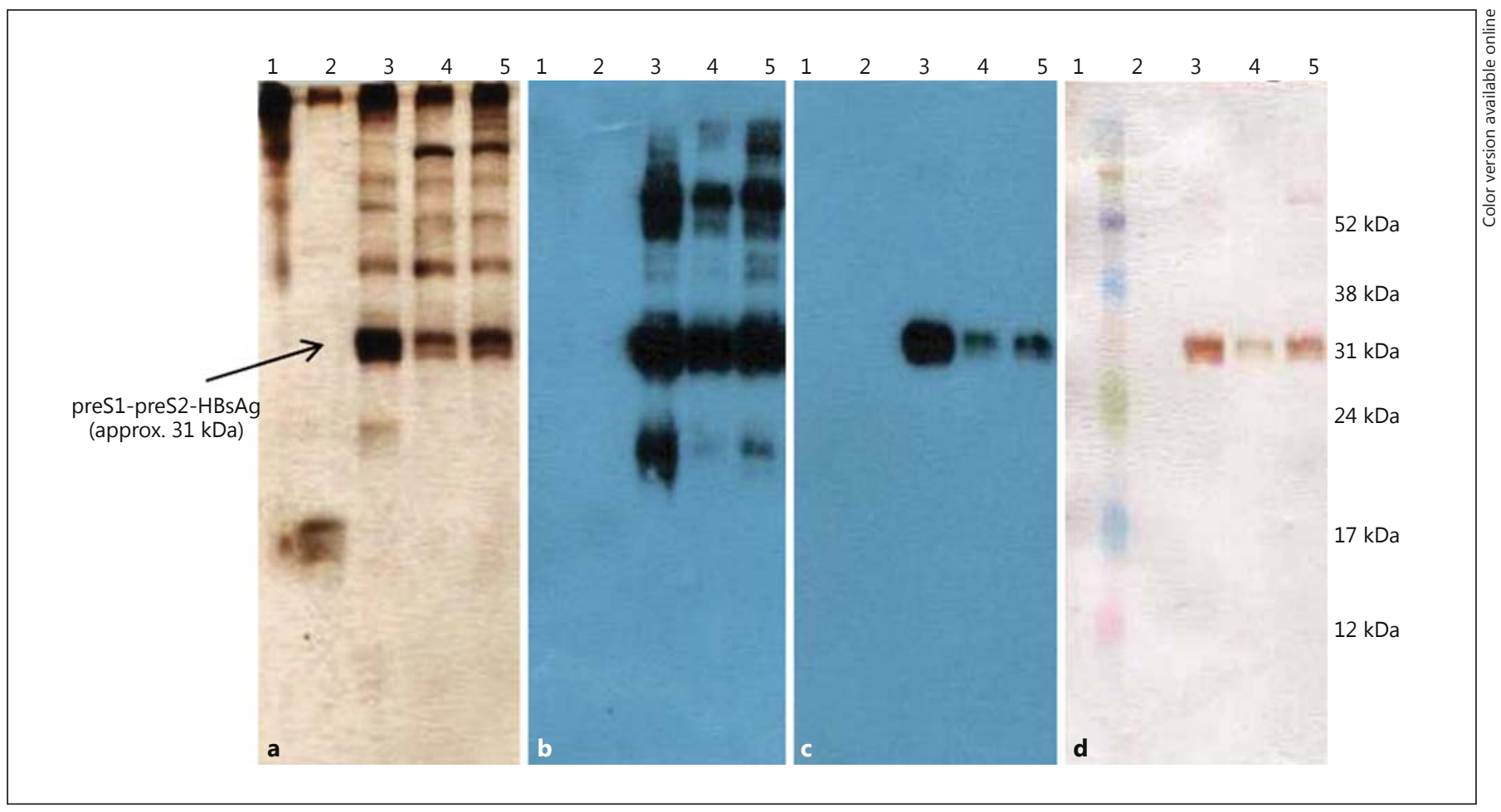

Fig. 4. SDS-PAGE (a) and Western blots (b-d) of preS1-preS2HBs preparations. Approximately $10 \mu \mathrm{g}$ of the purified antigen of 3 different preparations (lanes 3, 4, and 5) was submitted to electrophoresis. Yeast-expressed pB166 (see Fig. 3 legend) was used as the negative control (lane 2) for the Western blots. For SDS-PAGE, gel was stained with silver nitrate. In Western blots, anti-preS1 (b), anti-preS2 (c), and anti-HBs (d) mAbs were used and the reactions were revealed with either ECL $(\mathbf{b}, \mathbf{c})$ or $\mathrm{DAB}(\mathbf{d})$. The marker used was Amersham Rainbow RPN756E.
Fig. 5. SDS-PAGE (a) and Western blots (b, c) of $\mathrm{HBcAg}$ preparations. Approximately $10 \mu \mathrm{g}$ of the purified antigen of 3 different preparations (lanes 2, 4, and 5) was submitted to electrophoresis. HBsAg (see Fig. 4 legend) was used as the negative control. For SDS-PAGE, gel was stained with silver nitrate, and for Western blot, an anti-HBcAg $\mathrm{mAb}$ was used and the reaction was revealed with ECL (b) and DAB (c). The marker used was Amersham Rainbow RPN756E.

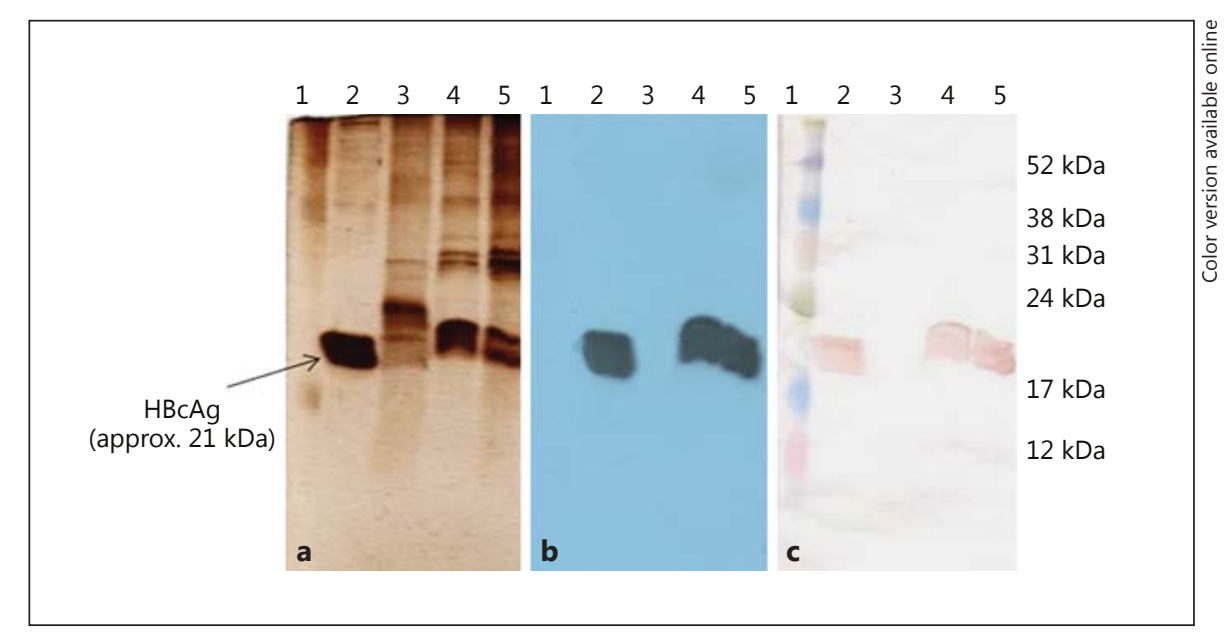

nized with HBsAg, the reactivity obtained by immunization with 2 doses of $0.5 \mu \mathrm{g} /$ dose/animal was improved significantly (Fig. 6b2). For anti-preS2 antibodies, a high reactivity was obtained by immunization with 2 doses of $0.5 \mu \mathrm{g} /$ dose/animal (Fig. 6b3). With $\mathrm{HBcAg}$, even a single dose with $0.2 \mu \mathrm{g} / \mathrm{animal}$ elicited antibodies with reactivity that was statistically significant in comparison with the immunization with HBsAg (Fig. 6c).

For the immunization with a combination of the 3 antigens in a unique inoculum, reactivity increased with an
96

Intervirology 2017;60:90-101 DOI: $10.1159 / 000480509$
Granovski et al. 


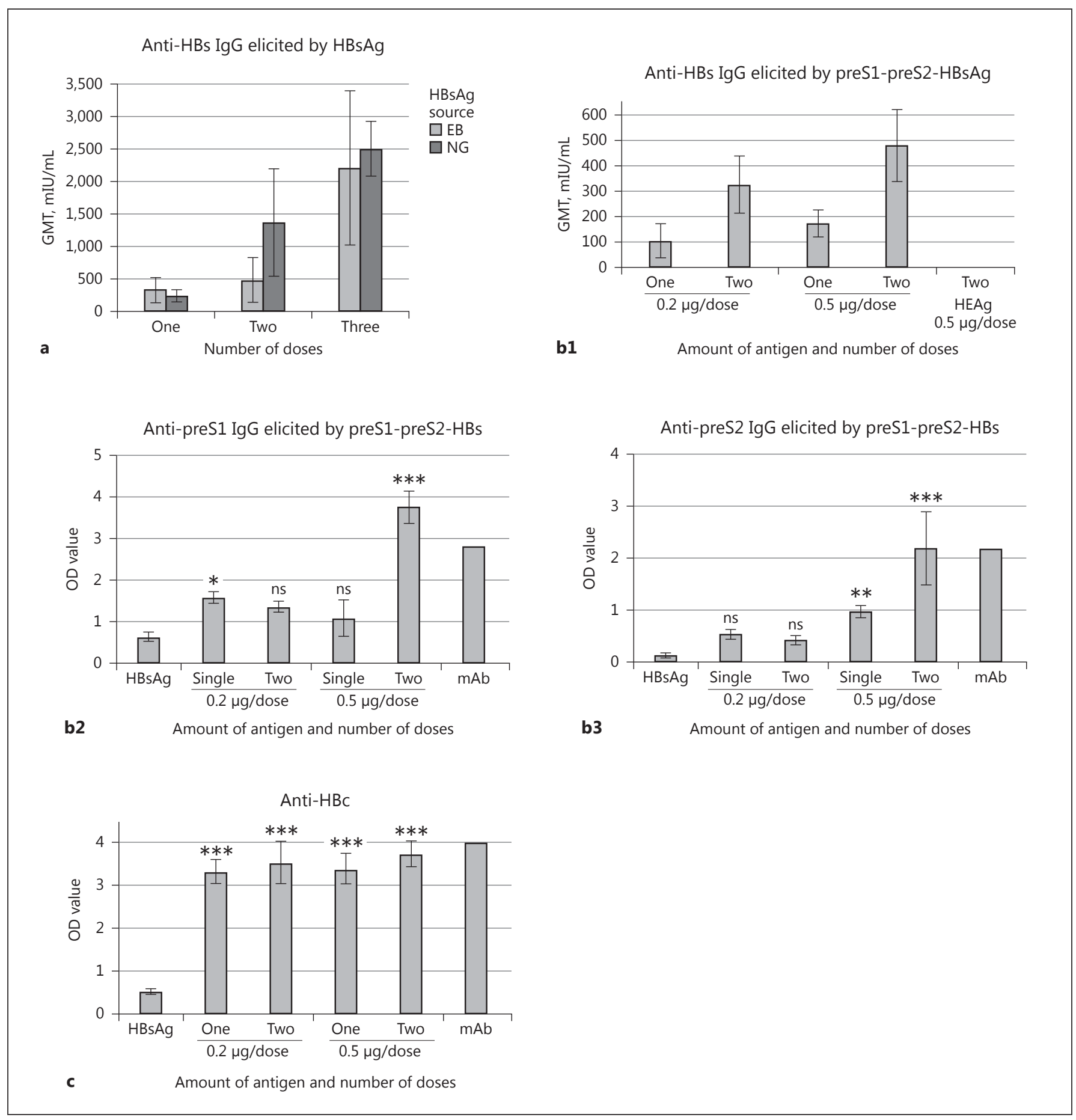

Fig. 6. ELISA data obtained by testing the serum samples of mice immunized with individual preparations of $\operatorname{HBsAg}(\mathbf{a})$, preS1-preS2HBsAg (b), and HBcAg (c). Groups of BALB/c mice were immunized with $0.2 \mu \mathrm{g}$ of $\mathrm{HBs}$ g from different sources (EB, Engerix B from GSK; NG, this study) per dose and per animal (a) or as indicated in the graphs. After the completion of the immunization schedules, the mice were bled and their serum samples were tested in ELISA for detection of the indicated antibodies. For anti-HBs (anti-S), reactivity levels are indicated as GMT (geometric mean titer) values (a, b1). For anti-preS1 (b2), anti-preS2 (b3), and anti-HBc (c) antibody detection, samples were tested against bacteria-expressed GSTpreS1, GST-preS2CA, or HBcAg (described in Materials and Methods) that were used to coat the ELISA plate wells, and the graphs represent raw $\mathrm{OD}_{492}$ values. Commercial $m A$ bs were used as controls in b2, b3, and c (the same used in the Western blots). Statistical analyses were carried out between the negative control group (mice immunized with HBsAg) and the test group. ${ }^{*} p<0.05$; ${ }^{* *} p<0.01$; ${ }^{* * *} p<0.001$. ns, not statistically significant.
Yeast-Derived New-Generation HBV

Vaccine
Intervirology 2017;60:90-101 DOI: $10.1159 / 000480509$ 
Fig. 7. ELISA data obtained by testing serum samples of mice immunized with the combined formulation of the 3 antigens. Each dose contained $0.02 \mu \mathrm{g}$ of HBsAg, 0.2 $\mu \mathrm{g}$ of preS1-preS2-HBs, and $0.02 \mu \mathrm{g}$ of $\mathrm{HBc}$ that was inoculated in each animal, with the number of doses per group indicated. Reactivity levels are indicated as GMT for anti-HBs or OD values for anti-preS1, antipreS2, and anti-HBc. As the negative control, samples were also tested against pB166, a fusion protein containing GST, and a truncated ORF2 protein of hepatitis $\mathrm{E}$ virus (anti-HEAg). The positive control was Engerix B (EB).

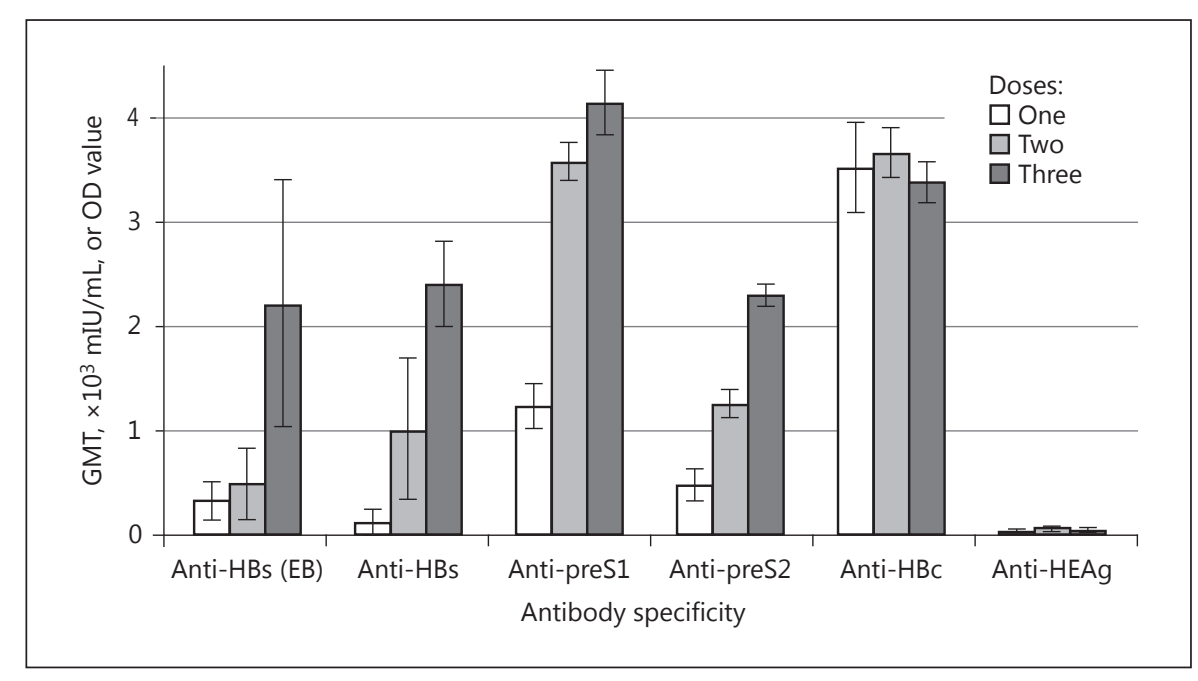

increasing number of doses, except for anti-HBc values, which remained similar regardless the number of doses (Fig. 7). For anti-preS2 antibodies, a third dose of the combined inoculum was required to reach $\mathrm{OD}$ values that were similar to those obtained with an individual administration of preS1-preS2-HBs (Fig. 6b3). These results indicate that there was low interference, if any, in the humoral response by combining the antigens for the immunization. In addition, GMT values obtained for anti-HBs antibodies elicited by the combined inoculum were comparable to a commercial $\mathrm{HBV}$ vaccine.

\section{Discussion}

In this study, we have described the expression of HBV antigens by fermentation in the methylotrophic yeast $H$. polymorpha and the humoral immune response of these antigens elicited in mice. This yeast has several advantages over the baker's yeast $S$. cerevisiae used in the production of the commercial HBV vaccines Engerix B (GSK) and RECOMBIVAX ${ }^{\circledR}$ HB (Merck). Some of the advantages involve culture in large-scale fermenters to higher cell densities, thermostability, stability in a high range of $\mathrm{pH}$ values (from 2.5 to 6.5), low glycosylation patterns, and a very well-controlled gene expression [29].

The extraction and purification processes were almost identical for all 3 antigens. The purification process was very similar to commercial analogs [30], contrasting in one crucial point - the use of $\mathrm{CsCl}$ in the ultracentrifugation process. Our process involved the use of $\mathrm{KBr}$ gradients and a final gel filtration chromatography to remove the salt.
During the purification, all 3 antigens displayed a particle behavior, showing high molecular weight structures observed during the tangential flow filtration, forming a single uniform band in $\mathrm{KBr}$ gradient isopycnic ultracentrifugation, and finally a single and well-defined profile in both SEC during the polishing step of the purification and the HPLC-SEC characterization during purity analysis. Despite the particle behavior, there is no clear evidence of virus-like particle formation which eventually could be demonstrated by electron microscopy and immunofluorescence. The final product characterization by HPLC showed a high purity of the antigens ( $\geq 97 \%$ for preS1preS2-HBs, and $\geq 98 \%$ for both $\mathrm{HBcAg}$ and HBsAg). The WHO recommendation for new HBV vaccines stipulates that the final bulk should have at least $95 \%$ purity [31].

Besides HPLC-SEC, SDS-PAGE was performed to evaluate each antigen. All antigens showed mobility in SDSPAGE that was in accordance with the predicted molecular weights based on their nucleotide sequences. For $\mathrm{HBsAg}$ and $\mathrm{HBcAg}$, their molecular weights were similar to those reported in other studies using yeast expression systems [32-35]. By using anti-HBs, anti-preS1, anti-preS2, and anti-HBc mAbs in Western blots, the results confirmed that antigens contained the sequences of interest.

The protein yields we obtained were considered high for a pilot scale, ranging from 104 (HBsAg) to 123 (HBcAg) and $132 \mathrm{mg} / \mathrm{L}$ (preS1-preS2-HBs) of culture. In larger fermenters, the conditions may be optimized and the yield increased several folds. For a second-generation HBV vaccine, containing the yeast-derived HBsAg, 1 preparation of the antigen would be enough to prepare approximately 50,000 pediatric doses with $10 \mu \mathrm{g}$ per dose for human immunization. For the immunization of mice, in each
Granovski et al. 
dose the combined formulation contained $0.2 \mu \mathrm{g}$ of HBs, $0.2 \mu \mathrm{g}$ of preS1-preS2-HBs, and $0.02 \mu \mathrm{g}$ of HBc, and following mice/human dose recalculation 1 batch of each of them would be enough to prepare over half a million doses.

The results of immunization with HBsAg alone showed that all mice seroconverted, even with a single dose containing $0.2 \mu \mathrm{g}$ of antigen, and the levels of antibodies were slightly higher than the immunization carried out with Engerix-B with 2 and 3 doses, although there were no statistically significant differences. Second-generation vaccines, such as Engerix- $B^{\circledR}$ and RECOMBIVAX ${ }^{\circledR} \mathrm{HB}$, are prepared with yeast-derived HBsAg and have been available since the mid-1980s [16]. These vaccines are used in approximately half of the world's countries and have proven to be safe and immunogenic.

Besides the small $\mathrm{HBs}$, third-generation $\mathrm{HBV}$ vaccines contain medium and, in some of them, large HBs expressed in mammalian cell cultures [16]. These vaccines are especially useful for people who do not respond to the yeast-derived vaccines $[15,16]$. Initial studies with Sci-B$\mathrm{Vac}^{\mathrm{TM}}$ (containing small, medium, and large HBs) showed that, in order to obtain a seroconversion rate of anti-HBs of $100 \%$ in $\mathrm{BALB} / \mathrm{c}$ mice with a unique dose, inoculation of approximately $0.81 \mu \mathrm{g}$ of antigen was needed in each animal [15]. In our study, the results showed that all immunized mice had anti-HBs seroconversion with a unique dose containing $0.2 \mu \mathrm{g}$ of preS1-preS2-HBs administered alone, which was approximately a quarter of the amount required with Sci-B-Vac ${ }^{\mathrm{TM}}$, a CHO-derived antigen. Only 1 animal in our experiment showed low antibody levels $(11.1 \mathrm{mIU} / \mathrm{mL})$ after a unique dose, although it was still above the protective level $(10 \mathrm{mIU} / \mathrm{mL})$. These results indicate that the yeast-derived preS1-preS2-HBs evaluated in this study showed higher immunogenicity with regard to the HBs sequence than Sci-B-Vac. In addition, $0.5 \mu \mathrm{g} /$ dose was required to obtain antibody responses to preS1 and preS2 sequences that were dependent on the number of doses that were administered (Fig. 6b2, b3). Furthermore, the cost of production of preS1-preS2-HBs in the yeast cell system is considerably lower in comparison to a mammalian cell system. The chimeric particle elicited good preS1 and preS2 IgG antibodies. However, the antiHBs present in the structure had low titers when compared to the HBsAg response alone, which might be due to the fact that small $\mathrm{HB}$ antigens carrying the preS1 and preS2 have epitopes hidden because of the conformational aspect or, possibly, because preS1 and preS2 are more immunodominant epitopes in the structure.

In addition to being used as a carrier of foreign epitopes to improve their immunogenicity [19-21], HBcAg has

Yeast-Derived New-Generation HBV

Vaccine been used to investigate its potential as either a prophylactic or therapeutic reagent, in this case for the treatment of chronic hepatitis B [36]. HBcAg induces a strong antibody response during HBV infection [18] and the recombinant form, derived from Escherichia coli, has been shown to provide substantial protection in chimpanzees $[22,37,38]$. In the animals in which the protection was not complete, the infection was mild, as indicated by the low and shortlived HBsAg titer [22], and when delivered as a DNA vaccine in mice it has elicited strong $\mathrm{T}$ cell and high titer antibody responses [39]. In our study, the yeast-derived $\mathrm{HBcAg}$ also induced a strong antibody response, both individually and in combination with the other antigens.

In the combined inoculum, the presence of $\mathrm{HBcAg}$ suppressed the antibody responses to the other antigens (data not shown), which were then restored by reducing the amount of the $\mathrm{HBcAg}$ in the inoculum to $0.02 \mu \mathrm{g}$. Still, even with this low amount of antigen in the combined formulation, the anti-HBc response remained strong, even with a single dose. Therefore, the antibody responses to all antigens present in the combined formulation were effective, especially after the completion of the 3-dose schedule.

Some questions may be raised about the utilization of $\mathrm{HBcAg}$ in vaccine formulations. Some countries use the $\mathrm{HBcAg}$ as a marker to detect HBV infection in the population, since the vaccination is performed using only HBsAg. To circumvent this issue, a marker change could be achieved by switching the HBcAg marker to the $\mathrm{HBeAg}$ marker. Also, the blood screening is only the first step of the HBV infection test, with PCR testing being the second step. Finally, the IgM and IgG screening can distinguish between immunized individuals and those infected, since anti-HBc IgM clears the system a week after vaccination, with only anti-HBc IgG prevailing. If an individual is infected and has acute viremia, the anti-HBc IgM will be present for a much longer period.

Current and third-generation HBV vaccines are each based on only 1 sequence belonging to a unique HBV subtype $[11,16]$. In our study, the combined formulation contains 2 HBsAg sequences, 1 of subtype ayw/genotype $\mathrm{D}$ and the other of subtype adw4/genotype F, present in preS1-preS2-HBs. These sequences are very divergent from each other, which may increase the protective efficacy of the combined formulation against infection caused by different HBV genotypes. In addition, HBV mutants have been found in some individuals who had been immunized by the hepatitis B second-generation vaccine $[40,41]$. These viral variants likely emerged due to the selective pressure caused by extensive hepatitis B

Intervirology 2017;60:90-101 DOI: $10.1159 / 000480509$ 
vaccination programs, and the aa substitutions originated by the mutations are mainly located in the a determinant of HBsAg, between aa position 124 and 147, which contains target epitopes of neutralizing antibodies. The preS1-preS2-HBs we constructed contain 1 preS1 sequence of genotype $\mathrm{A}$, and 3 preS2 sequences of genotypes $\mathrm{C}, \mathrm{A}$, and $\mathrm{B}$. While HBVs that carry substitutions in the a determinant may escape neutralization by antibodies elicited by HBsAg, these variants may be neutralized by anti-preS1 and anti-preS2 antibodies.

Recombinant $\mathrm{HBcAg}$, in combination with HBsAg, has been evaluated in chronic hepatitis B patients, resulting in normalized ALT levels in all of them and no detectable HBV DNA in half of them [36, 42]. These results support further evaluations of the combined HBV antigens we have reported in this study as therapeutic reagents.

Despite the IgG elicitation using the combined antigen obtained in this experiment, it is crucial to demonstrate the antibody specialization for different genotypes and subtypes of the formulation. Additionally, a virus neutralization assay could be of high value to demonstrate how well the antigens protect against infection and/or challenge.

In conclusion, we have described the successful construction, expression, and purification of $3 \mathrm{HBV}$ structural antigens, small HBsAg, a chimeric preS1-preS2$\mathrm{HBsAg}$, and $\mathrm{HBcAg}$ in a yeast-cell system. The evaluation of their antigenic properties showed that the sequences were properly expressed, by using specific mAbs, and the purified antigens had the expected molecular weights. We also assessed their immunogenic properties, showing that the antigens, individually or in combination, elicited anti-HBs, anti-preS1, anti-preS2, and anti-HBc antibodies efficiently in mice. The combined formulation may provide improved protection for low and nonresponders to the current vaccine and protect against a large variety of HBV genotypes/subtypes, as well as against HBV escape mutants. Also, its antigenic composition may be useful for the treatment of chronic carriers. Our findings show that these antigens are appropriate for further evaluation as a potential fourth-generation prophylactic vaccine as well as therapeutic vaccine.

\section{Study Limitations}

This study had limitations that can and will be addressed in the future. Although we observed the virus-like particle behavior of the antigens during purification and in analytical evaluation, there was no clear evidence of

particle formation. The formation of these structures is crucial for a high immune response and better protection against infection. The response obtained with purified antigens was satisfactory for the study, but a correct structure evaluation with immunofluorescence and/or electron microscopy may elucidate if the antibody titer was generated due to particle structure or not, and if the signal can be boosted with improved structures.

Also, there are some discrepancies in antibody generation from the chimeric preS1-preS2-HBsAg alone, showing low anti-HBs signals when compared to HBsAg. We believe that the cause of this can also be elucidated in further analysis of the chimera structure and additional serum evaluation.

\section{Acknowledgements}

The authors thank Dr. Nestor Pérez, Miriam Cedillo, and Octavio Escamilla of Probiomed S.A. de C.V., Mexico, for their assistance with the experiments involving the immunization of mice, and Dr. Juliana S. Miranda of Instituto de Ciências Biomédicas of Universidade Federal de Uberlândia, Brazil, for assistance with the statistical analyses.

\section{Ethics Statement}

All institutional and national guidelines for the care and use of laboratory animals were followed - document number $\mathrm{PB}(\mathrm{MB} 5)$, edition 4 under Mexican official normative NOM-062-ZOO-1999.

\section{Disclosure Statement}

The authors declare no conflicts of interest.

\section{References}

Intervirology 2017;60:90-101

DOI: $10.1159 / 000480509$
1 World Health Organization: Hepatitis B fact sheet. http://www.who.int/mediacentre/factsheets/fs204/en/ (accessed April 28, 2017).

2 Morikawa K, Shimazaki T, Takeda R, Izumi T, Umumura M, Sakamoto N: Hepatitis B: progress in understanding chronicity, the innate immune response, and cccDNA protection. Ann Transl Med 2016;4:337-343.

3 Gerlich WH: Medical virology of hepatitis B: how it began and where we are now. Virol J 2013; 10:239-263.

4 Marcellin P, Gane E, Buti M, Afdhal N, Sievert W, Jacobson IM, Washington MK, Germanidis G, Flaherty JF, Aguilar Schall R, Bornstein JD, Kitrinos KM, Subramanian GM, McHutchison JG, Heathcote EJ: Regression of cirrhosis during treatment with tenofovir disoproxil fumarate for chronic hepatitis B: a 5-year open-label follow-up study. Lancet 2013;381:468-475
Granovski et al. 
5 Kramvis A: Genotypes and genetic variability of hepatitis B virus. Intervirology 2014;57: 141-150.

6 Heermann KH, Goldmann U, Schwartz W, Seyffarth T, Baumgarten H, Gerlich WH: Large surface proteins of hepatitis B virus containing the pre-s sequence. J Virol 1984; 52:396-402.

7 Machida A, Kishimoto S, Ohnuma H, Baba K, Ito Y, Miyamoto H, Funatsu G, Oda K, Usuda S, Togami S: A polypeptide containing 55 amino acid residues coded by the pre-S region of hepatitis B virus deoxyribonucleic acid bears the receptor for polymerized human as well as chimpanzee albumins. Gastroenterology 1984;86:910-918.

8 Edey M, Barraclough K, Johnson DW: Review article: hepatitis B and dialysis. Nephrology 2010;15:137-145.

9 Mahoney RT: Cost of plasma-derived hepatitis B vaccine production. Vaccine 1990;8: 397-401.

10 André FE: Summary of safety and efficacy data on a yeast-derived hepatitis B vaccine. Am J Med 1989;87:14S-20S.

11 Shouval D: Hepatitis B vaccines. J Hepatol 2003;39(suppl 1):S70-S76.

12 Troisi CL, Hollinger FB: Hepatitis B vaccines. Prog Liver Dis 1990;9:405-442.

13 Yokosawa J, Perez NO, Rossi LMG: Recombinant vaccines against hepatitis viruses; in Khudyakov YE (ed): Medicinal Protein Engineering. Boca Raton, CRC Press, 2009, pp 299-315.

14 Rezaee-Zavareh MS, Einollahi B: Hepatitis B vaccination: needs a revision. Hepat Mon 2014;14:e17461.

15 Shouval D, Ilan Y, Adler R, Deepen R, Panet A, Even-Chen Z, Gorecki M, Gerlich WH: Improved immunogenicity in mice of a mammalian cell-derived recombinant hepatitis $B$ vaccine containing pre-S1 and pre-S2 antigens as compared with conventional yeastderived vaccines. Vaccine 1994;12:14531459.

16 Shouval D, Roggendorf H, Roggendorf M: Enhanced immune response to hepatitis $\mathrm{B}$ vaccination through immunization with a Pre-S1/Pre-S2/S vaccine. Med Microbiol Immunol 2015;204:57-68.

17 Zaffina S, Marcellini V, Santoro AP, Scarsella M, Camisa V, Vinci MR, Musolino AM, Nicolosi L, Rosado MM, Carsetti R: Repeated vaccinations do not improve specific immune defenses against Hepatitis B in non-responder health care workers. Vaccine 2014;32: 6902-6910.

18 Chisari FV, Ferrari C: Hepatitis B virus immunopathogenesis. Annu Rev Immunol 1995;13:29-60.
19 Arora U, Tyagi P, Swaminathan S, Khanna N: Chimeric hepatitis B core antigen virus-like particles displaying the envelope domain III of dengue virus type 2. J Nanobiotechnology 2012;10:30

20 Clarke BE, Newton SE, Carroll AR, Francis MJ, Appleyard G, Syred AD, Highfield PE, Rowlands DJ, Brown F: Improved immunogenicity of a peptide epitope after fusion to hepatitis B core protein. Nature 1987;330: 381-384.

21 Pumpens P, Ulrich RG, Sasnauskas K, Kazaks A, Ose V, Grens E: Construction of novel vaccines on the basis of virus-like particles: hepatitis $B$ virus proteins as vaccine carriers; in Khudyakov YE (ed): Medicinal Protein Engineering. Boca Raton, CRC Press, 2009, pp 205-248.

22 Murray K, Bruce SA, Wingfield P, van Eerd P, de Reus A, Schellekens H: Protective immunisation against hepatitis B with an internal antigen of the virus. J Med Virol 1987;23:101107.

23 Billioud G, Pichoud C, Puerstinger G, Neyts J, Zoulim F: The main hepatitis B virus (HBV) mutants resistant to nucleoside analogs are susceptible in vitro to non-nucleoside inhibitors of HBV replication. Antiviral Res 2011; 92:271-276.

24 Locarnini SA, Yuen L: Molecular genesis of drug-resistant and vaccine-escape $\mathrm{HBV}$ mutants. Antivir Ther 2010;15:451-461.

25 Granovski N: Processo de produção de HBsAg em grande quantidade para a fabricação de vacina. Brazil Patent PI No 9705324-4 B1. 2006.

26 Levine DW, Cooney CL: Isolation and characterization of a thermotolerant methanolutilizing yeast. Appl Microbiol 1973;26:982990.

27 Dohmen RJ, Strasser AW, Höner CB, Hollenberg CP: An efficient transformation procedure enabling long-term storage of competent cells of various yeast genera. Yeast 1991; 7:691-692.

28 Meng J, Dai X, Chang JC, Lopareva E, Pillot J, Fields HA, Khudyakov YE: Identification and characterization of the neutralization epitope(s) of the hepatitis E virus. Virology 2001; 288:203-211.

29 Hollenberg CP, Gellissen G: Production of recombinant proteins by methylotrophic yeasts. Curr Opin Biotechnol 1997;8:554-560.

30 De-Heyder K, Schu P, Serantoni M, Van-Opstal O: Purification of HBV antigens for use in vaccines. Glaxosmithkline Biologicals. US Patent No 20030235590 A1. 2014.
31 World Health Organization: Recommendations to assure the quality, safety and efficacy of recombinant hepatitis B vaccines. WHO Technical Report Series, No. 978. Geneva, WHO, 2013, pp 189-240.

32 Chen $\mathrm{H}$ : Expression and purification of the recombinant $\mathrm{HBcAg}$ core particles derived from methyltrophic Pichia pastoris, and TEM and AFM of the core particles and their natural aggregates. J Electron Microsc (Tokyo) 2007;56:235-242.

33 Gurramkonda C, Zahid M, Nemani SK, Adnan A, Gudi SK, Khanna N, Ebensen T, Lünsdorf H, Guzmán CA, Rinas U: Purification of hepatitis B surface antigen virus-like particles from recombinant Pichia pastoris and in vivo analysis of their immunogenic properties. J Chromatogr B Analyt Technol Biomed Life Sci 2013;940:104-111.

34 Huang Y, Bi J, Zhang Y, Zhou W, Li Y, Zhao L, Su Z: A highly efficient integrated chromatographic procedure for the purification of recombinant hepatitis B surface antigen from Hansenula polymorpha. Protein Expr Purif 2007;56:301-310.

35 Pointek M, Weniger M: Method for obtaining recombinant HBsAg. US Patent No US6428984 B1. 2002.

36 Ghasemi F, Rostami S, Ghayour-Mobarhan M, Meshkat Z: Current progress in the development of therapeutic vaccines for chronic hepatitis B virus infection. Iran J Basic Med Sci 2016;19:692-704.

37 Iwarson S, Tabor E, Thomas HC, Snoy P, Gerety RJ: Protection against hepatitis $B$ virus infection by immunization with hepatitis $B$ core antigen. Gastroenterology 1985;88:763767.

38 Murray K, Bruce SA, Hinnen A, Wingfield P, van Erd PM, de Reus A, Schellekens H: Hepatitis $B$ virus antigens made in microbial cells immunise against viral infection. EMBO J 1984;3:645-650.

39 Obeng-Adjei N, Choo DK, Saini J, Yan J, Pankhong P, Parikh A, Chu JS, Weiner DB: Synthetic DNA immunogen encoding hepatitis $B$ core antigen drives immune response in liver. Cancer Gene Ther 2012;19:779-787.

40 Carman WF, Zanetti AR, Karayiannis P, Waters J, Manzillo G, Tanzi E, Zuckerman AJ, Thomas HC: Vaccine-induced escape mutant of hepatitis B virus. Lancet 1990;336:325-329.

41 Zuckerman JN: Protective efficacy, immunotherapeutic potential, and safety of hepatitis B vaccines. J Med Virol 2006;78:169-177.

42 Al-Mahtab M, Akbar SM, Aguilar JC, Uddin MH, Khan MS, Rahman S: Therapeutic potential of a combined hepatitis B virus surface and core antigen vaccine in patients with chronic hepatitis B. Hepatol Int 2013;7:981989.
Yeast-Derived New-Generation HBV

Vaccine
Intervirology 2017;60:90-101

DOI: $10.1159 / 000480509$ 